\title{
PODIZANJE SUBJEKTA NA PRIMERU ITALIJANSKOG GLAGOLA SEMBRARE I SRPSKOG GLAGOLA IZGLEDATI
}

U radu analiziramo i poredimo upotrebu glagola subjekatskog podizanja subjekta sembrare i izgledati. Za razliku od italijanskih i srpskih modalnih i faznih glagola podizanja, koji spadaju među glagole obligatornog subjekatskog podizanja subjekta, sembrare i izgledati mogu se javiti i s podignutim subjektom i bez njega. Svoju ćemo analizu sprovesti na osnovu sledećih sintaksičkih parametara: 1) odsustvo podignutog subjekta uz glagole sembrare i izgledati/prisustvo podignutog subjekta uz glagole sembrare i izgledati, 2) tip konstrukcije upotrebljene u funkciji dopune glagola sembrare i izgledati u odsustvu podignutog subjekta/ tip konstrukcije upotrebljene u funkciji dopune glagola sembrare i izgledati u prisustvu podignutog subjekta i 3) upotreba glagola sembrare i izgledati u funkciji kongruentnih upravnih predikata u konstrukcijama s podignutim subjektom/upotreba glagola sembrare i izgledati u funkciji nekongruentnih upravnih predikata u konstrukcijama s podignutim subjektom.

Budući da se pod određenim uslovima i glagol sembrare i glagol izgledati mogu upotrebiti i kao glagoli subjekatske kontrole, predmet naše analize biće i tipovi konstrukcija koji se u ovom slučaju javljaju u funkciji njihovih dopuna.

Ključne reči: sembrare, izgledati, subjekatsko podizanje subjekta, subjekatska kontrola.

\section{Uvod}

U ovom radu analiziramo i poredimo sintaksičko ponašanje italijanskog glagola sembrare i njegovog srpskog ekvivalenta izgledati. Reč je o glagolima subjekatskog podizanja subjekta koji se javljaju i u konstrukcijama bez podignutog subjekta i u konstrukcijama s podignutim subjektom. U konstrukcijama bez podignutog subjekta, ovi se glagoli upotrebljavaju kao bezlični (uvek su u 3. licu jednine (sredjeg roda)) i dobijaju sentenci-

*_uudinama@yahoo.com 
jalnu dopunu, dok se u prisustvu podignutog gramatičkog subjekta upotrebljavaju ili kao kongruentni (u bilo kojem od tri lica jednine odnosno množine) ili kao nekongruentni upravni predikati (u 3. licu jednine (srednjeg roda)) i dobijaju dopunu u vidu infinitivne ili finitne konstrukcije ili se pak kombinuju s predikativnom dopunom.

U radu skrećemo pažnju i na činjenicu da se ova dva glagola pod određenim uslovima upotrebljavaju i kao glagoli subjekatske kontrole.

Najviše informacija o glagolima podizanja u italijanističkoj literaturi pronašli smo u Manzini et al. (1991), Graffi (1994), Salvi \& Vanelli (2004) i Donati (2008), dok u srbističkoj literaturi najznačajniji doprinos izučavanju fenomena podizanja predstavlja Moskovljević Popović (2008).

\section{Opšte karakteristike glagola podizanja u italijanskom i srpskom jeziku}

Pod podizanjem se podrazumeva pomeranje imeničke sintagme s pozicije subjekta finitne dopunske konstrukcije na poziciju subjekta nadređene strukture. Postoje, međutim, i glagoli koji dopuštaju da imenička sintagma na poziciji subjekta finitne dopunske konstrukcije migrira u nadređenu strukturu i unutar nje dobije funkciju objekta upravnog glagola. Glagolima podizanja smatraju se stoga svi oni glagoli u kombinaciji s kojima subjekat finitne konstrukcije upotrebljene u funkciji njihove sentencijalne dopune postaje ili može postati subjekat odnosno objekat unutar upravne klauze. ${ }^{1}$ Razlikujemo, dakle, subjekatsko i objekatsko podizanje subjekta.

Italijanski glagol sembrare 'izgledati, činiti se' (kao i sinonimni parere 'izgledati, činiti se') ${ }^{2}$ i njegov srpski ekvivalent izgledati (kao i sinonimni $(u)$ činiti se) $)^{3}$ tipični su glagoli subjekatskog podizanja subjekta. Njihovu upotrebu u italijanskom i srpskom jeziku ilustruju sledeći primeri:

1 Za detaljniju analizu fenomena podizanja v. Moskovljević Popović (2008), kao i Manzini et al. (1991), Graffi (1994), Salvi \& Vanelli (2004) i Donati (2008) i onde navedenu literaturu.

2 Ostali italijanski glagoli subjekatskog podizanja subjekta kojima se izražava subjektivni stav ili utisak jesu apparire 'izgledati, (u)činiti se', risultare 'pokazati se, ispostaviti se, ispasti; izgledati, (u)činiti se' itd.

3 Srpski glagoli subjekatskog podizanja subjekta kojima se iskazuje subjektivni stav ili utisak jesu i delovati, pričiniti se/pričinjavati se, priviđati se itd. 
PODIZANJE SUBJEKTA NA PRIMERU ITALIJANSKOG GLAGOLA SEMBRARE ...

(1)

$\begin{array}{llll}\text { a. (Mi) sembra } & \text { che } & \text { Luigi } & \text { sia } \\ \text { (Mi) izgleda } & \text { COMP } & \text { Luiđi biti-PRES.SBJV } \\ \text { un } & \text { ragazzo } & \text { intelligente. } \\ \text { ART } & \text { momak } & \text { pametan }\end{array}$

'Izgleda (mi) da je Luiđi pametan momak.'

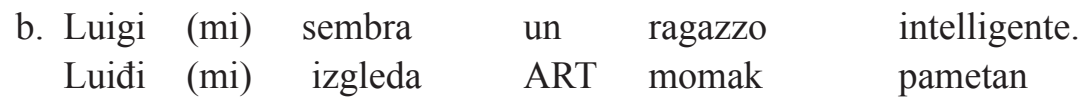

'Luiđi (mi) izgleda kao pametan momak.'

c. Luigi (mi) sembra essere un ragazzo intelligente.

Luiđi (mi) izgleda biti-INF.PRES ART momak pametan

'Luiđi (mi) izgleda kao pametan momak.'

d. (Mi) sembra che Luigi capisca tutto.

(Mi) izgleda COMP Luiđi razumeti-PRES.SBJV sve

'Izgleda (mi) da Luiđi razume sve.'

e. Luigi sembra capire tutto.

Luiđi izgleda razumeti-INF.PRES sve

'Izgleda da Luiđi razume sve.'

f. (Mi) sembra che Luigi abbia capito tutto.

(Mi) izgleda COMP Luiđi razumeti-PERF.SBJV sve

'Izgleda (mi) da je Luiđi sve razumeo.'

g. Luigi sembra aver capito tutto.

Luiđi izgleda razumeti-INF.PERF sve

'Izgleda da je Luiđi sve razumeo.'

h. Izgleda (mi) da je Marko odgovorna osoba.

i. Marko (mi) izgleda kao odgovorna osoba.

Kako pokazuju primeri (1a)-(1g), subjekatsko podizanje subjekta u italijanskom jeziku moguće je i s imenskim (up. 1a) s 1b) i 1c)) i s glagolskim predikatom (up. 1d) i 1e), kao i 1f) i 1g)). Imenička sintagma na poziciji subjekta sentencijalne dopune upravnog glagola sembrare podiže se na poziciju subjekta nadređene konstrukcije, pri čemu se predikat sentencijalne dopune transformiše u infinitivnu dopunu glagola sembrare (1c) 1e) i 1g)). Sadašnji infinitiv pri tome označava simultanost (1c) i 1e)), dok se prošlim (1g) iskazuje anteriornost radnje zavisnog $\mathrm{u}$ odnosu na radnju upravnog glagola. Takođe je bitno istaći da u konstrukcijama s podignutim subjektom zavisni glagol u infinitivu može biti izostavljen samo ukoliko 
je reč o infinitivu kopulativnog glagola essere, tj. jedino ako se subjekat podigao iz dopunske klauze s imenskim predikatom. U tom se slučaju uz glagol sembrare javlja samo predikativna dopuna (1b).

Primeri (1h) i (1i) ilustruju subjekatsko podizanje subjekta u srpskom jeziku na primeru glagola izgledati. Imenička sintagma na poziciji subjekta finitne klauze upotrebljene u funkciji dopune upravnog glagola pomera se na mesto subjekta nadređene strukture. U konstrukciji s podignutim subjektom zavisni kopulativni glagol jesam/biti po pravilu se gubi, dok upravni glagol podizanja dobija dopunu u funkciji predikativa (up. 1h) i 1i)). ${ }^{4}$

Što se tiče glagola izgledati, važno je naglasiti da se subjekatsko podizanje subjekta uobičajeno vezuje za prisustvo imenskog predikata u finitnoj konstrukciji upotrebljenoj u funkciji dopune ovog glagola. U nastavku rada detaljno ćemo analizirati sintaksičko ponašanje glagola izgledati i ispitati može li i on, poput italijanskog glagola sembrare, dopustiti podizanje subjekta i u slučajevima kad se kombinuje sa sentencijalnom dopunom u kojoj je upotrebljen glagolski predikat.

Primere objekatskog podizanja subjekta u italijanskom i srpskom jeziku nalazimo u sledećim rečenicama:
a. Giovanni ritiene che
Luigi sia
Đovani
smatra COMP
Luiđi
biti-PRES.SBJV
una
persona
irresponsabile.
ART
osoba
neodgovorna
'Đovani smatra da je Luiđi neodgovorna osoba.'
b. Giovanni ritiene Luigi una persona irresponsabile. Đovani smatra Luiđija ART osoba neodgovorna
'Đovani Luiđija smatra neodgovornom osobom.'
c. Marko smatra da je Ana vrhunska naučnica.
d. Marko Anu smatra vrhunskom naučnicom.

$4 \quad$ Čini se da se srpske konstrukcije bez podignutog subjekta u okviru kojih se imenski zavisni predikat, umesto u prezentu, kojim se iskazuje istovremenost s radnjom upravnog glagola, javlja u nekom drugom vremenu, kao npr. Izgleda da je Mile bio baš dobar čovek, ne mogu transformisati u konstrukcije s podignutim subjektom, a da pri tome upravni glagol izgledati dobije predikativnu dopunu i ostane u vremenu u kojem je inicijalno upotrebljen. 
U primerima (2a)-(2d) subjekat se podiže iz dopunske klauze u kojoj je u funkciji predikata upotrebljena imenska kopulativna konstrukcija. Imenička sintagma na poziciji subjekta finitne dopunske konstrukcije migrira u nadređenu strukturu i postaje direktni objekat upravnog glagola. Imenski predikat u zavisnoj konstrukciji nije, međutim, neophodan uslov za realizaciju objekatskog podizanja subjekta ni u jednom od dvaju jezika. ${ }^{5}$ Subjekat zavisne konstrukcije u kojoj je upotrebljen glagolski predikat može, naime, postati indirektni objekat nadređene strukture. To nam pokazuju sledeći, uzajamno sintaksički ekvivalentni, italijanski i srpski primeri:
a. Mara ha detto che Sara sa fare la ruota = Mara je rekla da Sara ume da napravi zvezdu
b. Di Sara Mara ha detto che sa fare la ruota $=$ Za Saru je Mara rekla da ume da napravi zvezdu

Pored tipičnih glagola subjekatskog podizanja subjekta kakvi su sembrare, njegov sinonim parere, izgledati i njegov sinonim (u)činiti se, i u italijanskom i u srpskom jeziku postoje i modalni i fazni glagoli subjekatskog podizanja subjekta. Za razliku od glagola sembrare, parere, izgledati i (u) činiti se, ${ }^{6}$ modalne i fazne glagole podizanja karakteriše nemogućnost formiranja korespondentnih konstrukcija bez podignutog subjekta, te se zato u vezi s njima govori o obligatornom subjekatskom podizanju subjekta. Tako npr. italijanski glagol sembrare i srpski glagol izgledati dopuštaju i konstrukcije bez podizanja i konstrukcije s podignutim subjektom, dok se italijanski fazni glagol cominciare 'početi' i srpski fazni glagol početi javljaju isključivo u konstrukcijama s podignutim subjektom (up. 4a) sa 4b) i 4c)).

(4) a. Mara ha cominciato a cantare = Mara je počela pevati/da peva
b. * ${ }^{\mathrm{E}}$ cominciato che Mara cantava.
AUX početi-PP COMP Mara pevati-IMP.IND
'*Počelo je da Mara peva.'
c. *Počelo je da Mara peva.

\footnotetext{
5 Za više informacija o glagolima objekatskog podizanja subjekta u srpskom jeziku v. Moskovljević Popović (2008: 92-94).

6 Za više informacija o ostalim glagolima neobligatornog subjekatskog podizanja subjekta u srpskom jeziku v. Moskovljević Popović (2008: 87-89).
} 


\section{Glagoli sembrare i izgledati kao glagoli subjekatskog podizanja subjekta}

U nastavku rada uporedićemo sintaksičko ponašanje italijanskog glagola sembrare i srpskog glagola izgledati.

Sintaksički parametri koje smatramo ključnima za opis i analizu upotrebe ovih dvaju glagola subjekatskog podizanja subjekta jesu sledeći: 1) odsustvo podignutog subjekta uz glagole sembrare i izgledati/prisustvo podignutog subjekta uz glagole sembrare i izgledati, 2) tip konstrukcije upotrebljene u funkciji dopune glagola sembrare i izgledati u odsustvu podignutog subjekta/tip konstrukcije upotrebljene u funkciji dopune glagola sembrare i izgledati u prisustvu podignutog subjekta i 3) upotreba glagola sembrare i izgledati u funkciji kongruentnih predikata u konstrukcijama s podignutim subjektom/upotreba glagola sembrare i izgledati u funkciji nekongruentnih predikata u konstrukcijama s podignutim subjektom.

3.1. U odnosu na prvi kriterijum, možemo reći da se i italijanski i srpski glagol javljaju u dvema konstrukcijama istog značenja - konstrukciji bez podignutog subjekta (1a), 1d), 1f) i 1h)) i konstrukciji s podignutim subjektom (1b), 1c), 1e), 1g) i 1i)).

U konstrukciji bez podignutog subjekta, ovi se glagoli ponašaju kao besubjekatski (bezlični) ${ }^{7}$ i dobijaju sentencijalnu dopunu s komplementi-

7 Bezličnim (besubjektaskim) glagolima smatramo glagole koji ne mogu otvoriti poziciju gramatičkom (nominativnom) subjektu, tj. ne mogu biti lično upotrebljeni, što znači da se uvek javljaju u 3. licu jednine (srednjeg roda). Ti se glagoli upotrebljavaju samo u bezličnim konstrukcijama bez se (Treba/Valja učiti, Treba/Valja da se uči, Treba/ Valja da svi ljudi uče, Grmi, Seva). Glagole koji otvaraju mesto gramatičkom subjektu i pri tome mu dodeljuju specifičnu semantičku ulogu nazivamo ličnim (subjekatskim) glagolima (Pokušavam učiti/Pokušavam da učim). U slučaju da se iz rečenične strukture u kojoj ovakvi glagoli vrše funkciju predikata ukloni subjekat, oni će biti upotrebljeni u bezličnoj ili, preciznije rečeno, obezličenoj se-konstrukciji (Pokušava se učiti/Pokušava se da se uči). Na pola puta između ove dve grupe glagola stoje glagoli subjekatskog podizanja subjekta. Oni mogu otvoriti ili otvaraju poziciju podignutom gramatičkom subjektu, ali mu ne dodeljuju semantičku ulogu. Tu ulogu podignutom subjektu zapravo dodeljuju od njih zavisni glagoli. Drugim rečima, kad je dopuna glagola subjekatskog podizanja subjekta neki bezličan (besubjekatski) glagol, i oni će se javiti u bezličnim konstrukcijama bez se (Počinje grmeti/Počinje da grmi; Izgleda da grmi/da je grmelo/da će grmeti). Kad im je dopuna lični (subjekatski) glagol, javljaju se ili s podignutim subjektom u ličnoj konstrukciji (Počinjem učiti/Počinjem da učim; Mile mi izgleda kao odgovorna osoba) ili 
zatorom che (1a), 1d) i 1f)) odnosno da (1h). Osim toga, uz njih se fakultativno javlja logički subjekat u dativu (1a), 1d), 1f) i 1h)).

U konstrukciji s podignutim gramatičkim subjektom, ovi se glagoli približavaju subjekatskim (ličnim) glagolima. ${ }^{8} \mathrm{U}$ tom se slučaju glagol sembrare kombinuje ili s infinitivnom dopunskom klauzom (1c), 1e) i 1g)) ili s predikativnom dopunom (1b), dok se glagol izgledati javlja s predikativnom dopunom (1i). Logički subjekat u dativu pri tome se fakultativno javlja i uz jedan i uz drugi glagol (1b), 1c) i 1i)). ${ }^{9}$

3.2. Drugi kriterijum se odnosi na finitne i infinitivne konstrukcije u funkciji dopune glagola sembrare i izgledati.

U odsustvu podignutog subjekta, italijanski glagol se kombinuje s finitnom dopunskom konstrukcijom koju čine komplementizator che i zavisni glagol u konjuktivu ili kondicionalu (1a), 1d) i 1f)). Vreme konjuktiva ili kondicionala zavisiće od tipa vremenskog odnosa koji se uspostavlja između zavisnog i upravnog predikata (simultanost, anteriornost, posteriornost). S druge strane, srpski glagol dobija sentencijalnu dopunu koja se sastoji od komplementizatora da i zavisnog glagola u odgovarajućem ličnom glagolskom obliku (1h).

Ukoliko pak dođe do podizanja subjekta sentencijalne dopune na poziciju subjekta nadređene strukture, glagol sembrare dobija dopunu u vidu sadašnjeg (1c) i 1e)) ili prošlog infinitiva (1g) zavisnog glagola ili se, u slučaju izostavljanja infinitiva kopulativnog glagola essere, kombinuje s predikativnom dopunom (1b). Srpski se glagol pak nikada ne upotrebljava

\footnotetext{
u bezličnoj se-konstrukciji, tj. konstrukciji iz koje je uklonjen podignuti subjekat, a umesto njega upotrebljena rečca se (Počinje se učiti/Počinje da se uči; ?Izgleda se odgovorno (<Ljudi izgledaju odgovorno)), s tim što glagol izgledati, kao glagol neobligatornog subjekatskog podizanja subjekta, u konstrukcijama bez podignutog subjekta može istovremeno biti i bezlično upotrebljen i kombinovati se s ličnim glagolima (Izgleda da Marko dosta uči). Moglo bi se, dakle, reći da glagoli subjekatskog podizanja subjekta mogu biti i bezlični i lični. Kad su lično upotrebljeni, još jednom ističemo, uz njih stoji podignuti subjekat, kojem semantičku ulogu ne dodeljuju oni, već od njih zavisni glagol.

$8 \quad$ V. fusnotu 7.

9 U italijanskom jeziku upotreba logičkog subjekta uz glagol sembrare nije uobičajena u konstrukcijama s podignutim gramatičkim subjektom i infinitivnom dopunom. Međutim, ukoliko je reč o infinitivu kopulativnog glagola essere, logički subjekat je već nešto učestaliji (v. (1c)).
} 
s infinitivom zavisnog glagola (odnosno s njegovim finitnim ekvivalentom $d a+$ prezent $)^{10}$, već dobija predikativnu dopunu (1i).

3.3. Dosad opisano sintaksičko ponašanje glagola sembrare i izgledati jeste ono koje se sreće u literaturi o glagolima podizanja u italijanskom i srpskom jeziku.

Kao što smo već istakli, podizanje subjekta iz konstrukcija upotrebljenih u funkciji sentencijalne dopune glagola izgledati uobičajeno se vezuje za prisustvo imenskog predikata (v. Moskovljević Popović, 2008: 87).

Što se pak tiče subjekatskog podizanja subjekta iz konstrukcija s glagolskim predikatom upotrebljenih u funkciji dopune ovog srpskog glagola (5a) i 5d)), smatramo da primeri poput (5b) i (5e) svedoče o tome da je proces podizanja "zahvatio" i njih, s tim što se realizuje u vidu konstrukcije s podignutim nominativnim subjektom i nekongruentnim ${ }^{11}$ upravnim predikatom, zbog čega takav vid podizanja možemo nazvati nekompletnim. ${ }^{12}$ Valja istaći da u ovakvim nekompletno podignutim konstrukcijama glagol podizanja u funkciji nekongruentnog upravnog predikata uvodi dopunsku klauzu koja se sastoji od komplementizatora da ili, eventualno, spoja kao $d a^{13}$ i zavisnog glagola u finitnom obliku.

\section{0 *Marko izgleda biti/da bude odgovorna osoba.}

11 Po našem sudu, upotreba pojedinih srpskih glagola u funkciji nekongruentnih upravnih predikata (izgleda, čini se, epistemičko mora (biti), epistemičko treba i deontičko treba) može se objasniti jedino teorijom podizanja (Izgleda/Čini se da Marko i Petar sve razumeju>Marko i Petar izgleda/čini se da sve razumeju; Mora (biti) da Marko i Petar sve razumeju>Marko i Petar mora (biti) da sve razumeju; Treba da su deca već stigla kući>Deca treba da su već stigla kući; Treba da deca budu u školi pre osam ujutro>Deca treba da budu u školi pre osam ujutro). Klikovac (2011) i Arsenijević \& Simonović (2014) registruju i opisuju neke od gore pomenutih nekongruentnih predikata, ali ne nude objašnjenje ove pojave koje bi bilo zasnovano na teoriji subjekatskog podizanja subjekta.

12 Kao što je već pomenuto, i glagol činiti se može se javiti kao nekongruentni predikat u kombinaciji s podignutim subjektom, pri čemu klitika uvek stoji iza njega (Marko i Petar čini se da sve razumeju<Čini se da Marko i Petar sve razumeju). Osim toga, moglo bi se reći da nekompletno subjekatsko podizanje subjekta ne podrazumeva samo glagolske, već i imenske zavisne predikate (Marko i Petar izgleda da/??kao da su odgovorne osobe<Izgleda da su Marko i Petar odgovorne osobe; Marko i Petar izgleda da/??kao da su bili dobri<Izgleda da su Marko i Petar bili dobri), s tim što nam se čini da je u slučaju imenskih zavisnih predikata gramatičnost konstrukcija koje sadrže spoj kao da krajnje upitna.

Moglo bi se reći da i Nikolić $(2018:$ 395, 397) smatra da u kombinaciji s uprav- 
Budući da je, po našem sudu, ovde reč o procesu podizanja koji je u toku, logično je da postoji mogućnost da se nekongruentni predikat pretvori u kongruentni. S tim u vezi, postavlja se pitanje da li se to već dogodilo u strukturama s nominativnim subjektom, glagolom izgledati kao kongruentnim upravnim predikatom i dopunskom konstrukcijom s komplementizatorom $d a$ ili spojem $k a o d a^{14}(5 \mathrm{c})$ i 5f) $)^{15}$ i zavisnim glagolom u finitnom obliku. $^{16}$

a. Izgleda da Marko i Petar sve razumeju.

b. Marko i Petar izgleda da sve razumeju/Marko i Petar izgleda kao da sve razumeju. ${ }^{17}$

nim glagolima izgledati, činiti se, delovati veznički spoj kao da uvodi dopunsku rečenicu koja nema poredbeno značenje.

14 Logično je postaviti i pitanje može li spoj kao da biti ekvivalent komplementizatoru $d a$ i u konstrukcijama bez podizanja, u kojima se glagol izgledati javlja s fakultativnim logičkim subjektom i sentencijalnom dopunom (up. Izgleda (mi) da su Marko $i$ Petar odgovorne osobe i Izgleda (mi) kao da su Marko i Petar odgovorne osobe).

15 Čini nam se da je u ovom specifičnom tipu kompletnog subjekatskog podizanja subjekta (bez obzira je li reč o glagolskim (5c) i 5f)) ili imenskim zavisnim predikatima (v. fusnotu 16)) gramatičnost dopunskih konstrukcija s komplementizatorom $d a$ vrlo upitna.

16 Ova vrsta kompletnog subjekatskog podizanja subjekta može se realizovati i iz finitnih dopunskih konstrukcija s imenskim predikatom (Marko i Petar izgledaju kao da/??da su odgovorne osobe<Izgleda da su Marko i Petar odgovorne osobe; Marko i Petar izgledaju kao da/l??da su bili dobri<Izgleda da su Marko i Petar bili dobri).

17 Primere upotrebe konstrukcija iz (5b) i (5e), sastavljenih od gramatičkog subjekta, nekongruentnog upravnog predikata i da/kao da-klauze, pronalazimo u Klikovac (2011: 16), u Arsenijević \& Simonović (2014: 9), u vlastitoj spontanoj govornoj produkciji, u spontanoj govornoj produkciji svojih sagovornika, na internetu. U nastavku navodimo neke od njih: Iako je čovek drugačiji od svih živih bića, okrutni zakoni opstanka čini se da u ljudskom svetu dolaze do posebnog izražaja (Klikovac, 2011: 16); Gospodine Stojanoviću, vi izgleda da ne znate čemu služe domovi kulture (https://www.radiokim.net/ vesti/?func=comment_list\&Aid=68717); Gospodo, vi izgleda da ste srećni što su milioni i milioni ljudi nezaposleni i siromašni (https://beleznica.wordpress.com/2011/07/04/poruka-iz-evropskog-parlamenta); Prema njegovim rečima, mladi izgleda da bolje reaguju na antidepresive za lečenje depresije i anksioznosti od dece (https://www.stetoskop.info/ upotreba-lekova/antidepresivi-efikasni-kod-mladih-i-dece); Ja izgleda da sam se zaljubila u njega (http://www.teen385.com/savjeti/pitanja-odgovori/daaaaajteee-odgovoooriiteee); Naprotiv, Vi izgleda kao da ste polazili od suprotnih načela (http://www.svedok.rs/ index.asp?show=76910) itd. Treba, međutim, skrenuti pažnju i na rečenice poput Marko 
c. Marko i Petar izgledaju kao da sve razumeju/??Marko i Petar izgledaju da sve razumeju.

d. Izgleda da su Marko i Petar sve razumeli.

e. Marko i Petar izgleda da su sve razumeli/Marko i Petar izgleda kao da su sve razumeli.

f. Marko i Petar izgledaju kao da su sve razumeli/??Marko i Petar izgledaju da su sve razumeli.

g. Sembra che gli studenti capiscano tutto. Izgleda COMP ART studenti razumeti-PRES.SBJV sve 'Izgleda da studenti sve razumeju.'

h. Gli studenti sembra che capiscano tutto. ART studenti izgleda COMP razumeti-PRES.SBJV sve 'Studenti izgleda da razumeju sve.'

Što se tiče glagola sembrare, pokazali smo da dopušta podizanje subjekta $\mathrm{i}$ iz sentencijalnih dopuna s imenskim (up. 1a), 1b) i 1c)) i iz sentencijalnih dopuna s glagolskim predikatom (up. 1d) i 1e)). Pri tome je, u prisustvu podignutog subjekta, upotrebljen u funkciji kongruentnog predikata, dok se od njega zavisni glagol javlja u sadašnjem ili prošlom infinitivu.

Međutim, i ovaj se glagol, poput srpskog glagola izgledati, u prisustvu podignutog subjekta može upotrebiti kao nekongruentni upravni predikat koji dobija dopunu u vidu finitne konstrukcije (up. 5g) i 5h)). U tom se slučaju obično govori o levoj dislokaciji, u čijoj osnovi može biti ili topikalizacija ili fokalizacija.

\section{Glagoli sembrare i izgledati kao glagoli subjekatske kontrole}

Pod određenim uslovima glagoli sembrare i izgledati mogu biti upotrebljeni i kao glagoli kontrole. U takvim konstrukcijama uspostavlja se koreferentnost između logičkog subjekta nadređene strukture i neekspliciranog subjekta dopunske klauze. Reč je, dakle, o jednom tipu subjekatske kontrole. ${ }^{18}$

i Petar, izgleda, sve razumeju/Marko i Petar su, izgleda, sve razumeli, u kojima je 3. lice jednine prezenta glagola izgledati upotrebljeno kao marker epistemičke modalnosti.

18 Za više informacija o fenomenu kontrole v. Moskovljević Popović (2008) i onde navedenu literaturu. 
Italijanska dopunska konstrukcija u ovom slučaju ima oblik $d i+($ sadašnji ili prošli) infinitiv (6a) i 6b)), dok se srpska sastoji od komplementizatora $d a$ i glagola u finitnom obliku (6c) i 6d)). ${ }^{19}$
a. Le sembra di
capire
tutto.
Joj izgleda PREP
razumeti-INF.PRES
sve
'Čini joj se da sve razume.'
b. Le sembra di
di
aver capito
tutto.
Joj izgleda
razumeti-INF.PERF
sve
'Čini joj se da je sve razumela.'
c. Izgleda mi da ništa ne razumem.
d. Izgleda mi da ništa nisam razumela.
e. Izgleda mi da ništa ne razumeš.
f. Izgleda mi da ništa nisi razumeo.

Postoji, međutim, jedna bitna razlika između italijanskog i srpskog glagola. U konstrukcijama s glagolom sembrare, logički subjekat je obligatorni kontrolor neiskazanog subjekta infinitivne dopunske klauze (6a) i 6b)), dok je u konstrukcijama s glagolom izgledati, logički subjekat tek opcioni kontrolor neekspliciranog subjekta finitne dopunske klauze (up. 6c) i 6e), kao i 6d) i 6f)). S tim u vezi, treba još jednom istaći da srpski glagol izgledati, za razliku od svog italijanskog ekvivalenata, nikada ne dobija dopunu u vidu infinitiva, bez obzira na to da li je upotrebljen kao glagol opcione kontrole ili kao glagol subjekatskog podizanja subjekta.

Treba takođe naglasiti da se glagoli sembrare i izgledati mogu javiti i bez logičkog subjekta koreferentnog sa subjektom zavisne konstrukcije, ali se u tom slučaju više ne može govoriti o subjekatskoj kontroli. Osim toga, ukoliko ne postoji koreferentnost logičkog subjekta upravnog glagola i subjekta dopunske klauze, zavisni glagol u italijanskom jeziku ne javlja se u infinitivu, već u finitnom obliku, tj. u konjuktivu ili kondicionalu (up.

19 Važna karakteristika glagola upotrebljenih u funkciji dopune glagola kontrole (uključujući i one s funkcijom dopune glagola kontrole sembrare i izgledati) jeste to što mogu otvoriti poziciju (gramatičkom) subjektu i dodeliti mu semantičku ulogu. Kontrola se, naime, zasniva upravo na koreferentnosti neiskazanog subjekta zavisne strukture i subjekta (gramatičkog ili logičkog) odnosno objekta upravnog glagola. S druge strane, kad su upotrebljeni kao glagoli podizanja, sembrare i izgledati ne podležu ovakvoj restrikciji. Dopune glagola podizanja mogu, naime, biti i besubjekatski glagoli. O ostalim razlikama između glagola kontrole i glagola podizanja v. Moskovljević Popović (90-91, 96-98). 
7a) i 7b)). Upravo ovakve konstrukcije, sastavljene od glagola sembrare i njegove sentencijalne dopune (7b), kao uostalom i korespondentne srpske konstrukcije sačinjene od glagola izgledati i njegove sentencijalne dopune, jesu one iz kojih se imenička sintagma na poziciji subjekta zavisne podiže na mesto subjekta upravne strukture (up. 7b) i 7c)).

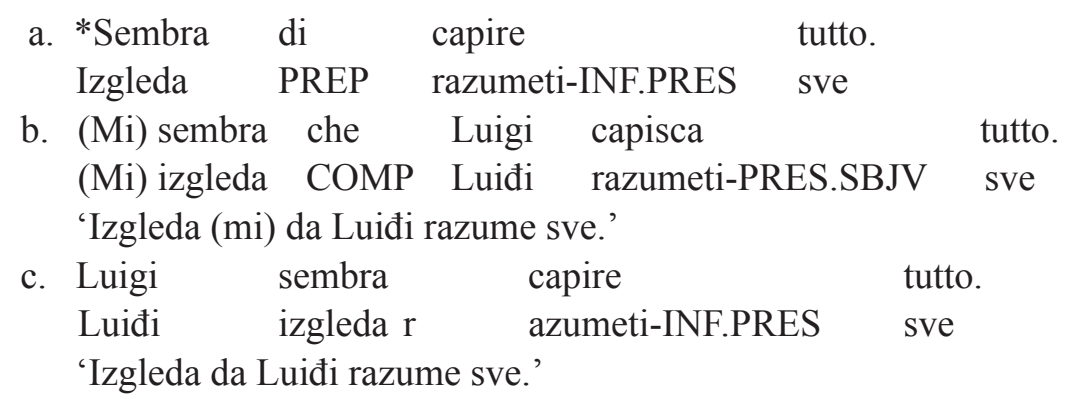

\section{Zaključak}

$\mathrm{S}$ jedne strane, smatramo da kontrastivna analiza sintaksičkog ponašanja glagola sembrare i izgledati koju smo u ovom radu sproveli može naći svoju didaktičku primenu. S druge strane, ta nam je analiza omogućila da uvidimo da se u srpskom jeziku subjekat može podići i iz sentencijalne dopune upravnog glagola izgledati u kojoj je upotrebljen glagolski predikat, kao i da se, u prisustvu podignutog subjekta, glagoli sembrare i izgledati mogu javiti i kao kongruentni i kao nekongruentni upravni predikati. $\mathrm{S}$ tim u vezi, identifikovali smo sve tipove dopuna ovih dvaju glagola, $\mathrm{tj}$. dopune koje dobijaju u odsustvu podignutog subjekta, u prisustvu podignutog subjekta, u slučajevima kad su upotrebljeni kao kongruentni i u slučajevima kad su upotrebljeni kao nekongruentni predikati.

Rad je poslužio i da se skrene pažnja na činjenicu da i italijanski i srpski glagol pod izvesnim uslovima mogu biti upotrebljeni i kao glagoli subjekatske kontrole.

Ostaje nam da se u nekom budućem istraživanju temeljnije pozabavimo analizom finitnih konstrukcija s komplementizatorom (kao) da upotrebljenih u funkciji dopune glagola izgledati, ali i morfološkom strukturom i sintaksičkom funkcijom neglagolskih dopuna ovog glagola, za šta u ovom radu nismo imali vremena, a sigurno bi nam moglo reći nešto novo o srpskom glagolu izgledati. 


\section{LITERATURA}

Arsenijević, B., \& Simonović, M (2014). Ličnost i bezličnost srpskog glagola trebati: Avanture teorijske lingvistike u prenormiranom domenu. Jezik, književnost, marginalizacija, 278-304.

Graffi, G. (1994). Sintassi. Bologna: Il Mulino.

Donati, C. (2008). Sintassi. Bologna: Il Mulino.

Klikovac, D. (2011). Još jednom o glagolu trebati: teorija, upotreba i norma. Naš jezik, XLII, 3/4, 3-23.

Manzini, M. R., Salvi, G., \& Skytte, G. (1991). Frasi subordinate all'infinito. In L. Renzi \& G. Salvi (ed), Grande grammatica italiana di consultazione II (pp. 483-569). Bologna: Il Mulino.

Moskovljević Popović, J. (2008). Ogledi o glagolskoj potkategorizaciji. Beograd: Čigoja štampa.

Nikolić, M. (2018). Rečenice s poredbenom klauzom. In P. Piper et al. (ed), Sintaksa složene rečenice u savremenom srpskom jeziku (pp. 385-420). Novi Sad: Matica srpska.

Salvi, G., \& Vanelli, L. (2004). Nuova grammatica italiana. Bologna: Il Mulino.

Milena D. Popović Pisarri

SOLLEVAMENTO DEL SOGGETTO: IL VERBO

ITALIANO SEMBRARE E IL SUO EQUIVALENTE SERBO IZGLEDATI

\section{Riassunto}

In questo lavoro vengono analizzati e confrontati i verbi a sollevamento del soggetto sembrare e izgledati. A differerenza dei verbi modali e aspettuali a sollevamento, con i quali il sollevamento del soggetto della subordinata alla posizione di soggetto della principale è obbligatorio in entrambe le lingue, i verbi sembrare e izgledati possono essere usati anche senza un soggetto sollevato. Viene condotta un'analisi sintattica contrastiva sulla base dei seguenti criteri: 1) assenza di un soggetto sollevato con i verbi sembrare e izgledati/presenza di un soggetto sollevato con i verbi sembrare e izgledati, 2) tipo di costrutto usato in funzione di complemento dei verbi sembrare e izgledati in assenza di soggetto sollevato/ 
tipo di costrutto usato in funzione di complemento dei verbi sembrare e izgledati in presenza di soggetto sollevato e 3) uso di sembrare e izgledati in funzione di predicato reggente concordato nelle costruzioni a sollevamento del soggetto/uso di sembrare e izgledati in funzione di predicato reggente non concordato nelle costruzioni a sollevamento del soggetto.

Dato che, a determinate condizioni, sia sembrare che izgledati possono fungere da verbi a controllo del soggetto, ci si propone anche di analizzare e confrontare le costruzioni infinitivali e di modo finito che in questo caso hanno la funzione del loro complemento verbale.

Parole chiave: sembrare, izgledati, sollevamento del soggetto, controllo del soggetto. 